\title{
Flexural behaviour of hybrid fiber reinforced concrete beam using BFRP bars
}

\author{
Guntupally Nikhil ${ }^{1}, K$. Hemalatha ${ }^{2}, V$ Mallikarjuna Reddy ${ }^{3}, V$. Swamy $\mathrm{Nadh}^{4}$ \\ ${ }^{1}$ Post-Graduation Student, Department of Civil Engineering, Gokaraju Rangaraju Institute of Engineering and Technology, Hyderabad, \\ Telangana, 500090, India. \\ ${ }^{2}$ Assistant Professor, Department of Civil Engineering, Gokaraju Rangaraju Institute of Engineering and Technology, Hyderabad, \\ Telangana, 500090, India. \\ ${ }^{3}$ Professor \&Head, Department of Civil Engineering, Gokaraju Rangaraju Institute of Engineering and Technology, Hyderabad, \\ Telangana, 500090, India. \\ ${ }^{4}$ Assistant Professor, Department of Civil Engineering, Aditya College of Engineering, Surampalem, Andra Pradesh 533437, India.
}

\begin{abstract}
The corrosion of rebar is one of the main problem in the construction industry. A lot of amount is spent on the repair work every year but none of them is that effective. Therefore, the recent studies are being conducting on the FRP rebar due to the brittle nature and the bonding performance. We have also used PVA fiber in concrete to increase the strength of the concrete. we are using Hybrid beams in which we have replaced the corner rebar with BFRP bars because of their superior corrosion effect and the strength to weight ratio. We used four point loading test on these hybrid reinforced beams to find the flexural behaviour by which we can predict the performance. $0.25 \%$ PVA fiber reinforced concrete showed the optimum results.
\end{abstract}

\section{Introduction}

Fiber-reinforced polymer is an alternative construction material and has been used as a substitute for steel in the construction industry for several decades. However, there are several weaknesses of FRP rebars, which are needed to be enhanced because of which the usage of the material is limited in civil infrastructures to reduce these disadvantages of using FRP, the concept of hybridization is introduced. The introduction of a hybrid structure includes cost-effectiveness. As there are some of the disadvantages in Fiber Reinforced concrete structures, so to improve these properties, a new model has been introduced and are being studied. The researchers have explained that the hybrid rebars are composed of many different fibers, the behaviour are mostly similar to that of steel rebars. The ductility of RC beams reinforced with 2 steel and 2 FRP rebars was also similar to that of steel RC beams. In all reinforced concrete structures, the corner steel bars that get corroded in the structure are mentioned (Qu and Zhang): 1 exposure of oxygen \& water, 2) resistance is less towards spalling than in other Cross sectional parts and 3 ) high carbonation rates. Then the corrosion from the outer side of steel bars spreads to the inner side of the reinforcement. The most commonly used FRP bar along with Steel is a Glass Fiber-reinforced polymer rebar it has a good and successful alternative that has various advantages than that of the traditional reinforcement method, which gives a longer service life. The BFRP rebar is a structural ribbed reinforcing bar product of excessive power and corrosion-resistant glass fiber which are impregnated and sure by an exceptionally long-lasting polymeric epoxy resin. Infeature houses are ideal for any harsh and corrosive environments. BFRP rebar is much lighter in weight than the same strength of steel rebar. It is very much less complicated to handle and in maximum cases, only one truck of steel is enough to bear the load for a whole project. Many researchers have tested the flexural conduct of hybrid BFRP/steel R C beams. The maximum load carrying capacity, crack width, and deflections were predicted in many research papers by experimental, numerical, etc methods. The use of steel reinforcement with FRP reinforcement in combinations increases the flexural strength of the beams. The ratio of reinforcement is the main factor that explains the ultimate moment of the beams, however, axial stiffness value between the BFRP \& Steel bars have some effect on the flexural ability. The load deflection reaction of hybrid BFRP/steel RC beams may be classified into 3 parts. In the 2 nd $\&$ 3rd part, flexural stiffness will increase with change in reinforcement ratio. The steel reinforcements enhance the ductility of the hybrid RC beams. The researchers have not only replaced the steel rebars in reinforced concrete structures with FRP rebars to improve the properties of the members of a structure. There were many experiments conducted on hybrid reinforced beams in recent times. Tan tested the many $\mathrm{RC}$ beams with Aramid FRP \& steel rebars are found that once the usage from Aramid FRP bars becomes not extra than one-1/2 of whole reinforcement, the hybrid Aramid 
FRP-metal strengthened RC beams have average serviceability. The Researchers have tested many Reinforced beams with BFRP and steel rebars. Silarbi has tested beams reinforced with Carbon FRP and steel bars and many other researchers have conducted various tests on hybrid reinforced beams. All these experiments lead to a conclusion that the tensile strength factor of the steel reinforcement reaches the maximum yield strength while the stress in FRP RC beam reaches a minute percentage of its ultimate value.

Now a days the impact of association of Fiber Reinforced Polymer bars and steel bars on the durability of members are studied. The researches have determined that using Fiber Reinforced Polymer rebars close to the corner of the tensile area and steel rebars used in middle or center of the tensile area offer the most advantage for the structure durability. They have also taken the consideration of different types of arrangements. There are many different types of arrangement like single layer in this type of arrangement all rebars are placed at the bottom of member in a single line with a definite distance between each rebar where there is maximum tensile strength that can be exerted. The next type of arrangement of reinforcement is double layer reinforcement in this type the reinforcement bars are arranged in two layers in different ways such as one layer of steel rebars and another with FRP rebars, by alternate steel and FRP rebars the bars can be arranged many possible ways of arrangement. They can also be arranged in a bundle form only a few researchers have conducted the test on this arrangement in this the researchers have tied either 1 steel, 1FRP or 2 FRP or 2 steel or all bars are tied at one place the placement of bars also plays a very vital role in the strength of the structure. Not only does the arrangement of steel rebars play a major role in the strength of the building but also the stirrups are very important. The angle of the hook also helps to increase the strength. Stirrups are mostly used are steel in the experimental as FRP bars cannot be bent so steel is used as it makes the work easy.

\section{Material}

In this project, we have used OPC 53 grade Cement as a binder for the fine and coarse aggregates which give strength to the concrete and used PVA fibers in concrete, and partially replaced steel rebars with Basalt fiber rebars for the reinforcement of concrete. The material used is shown in the figure.

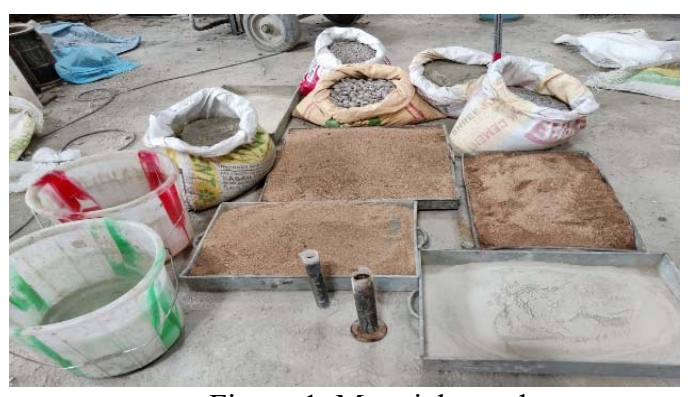

Figure 1. Materials used

\subsection{Cement}

We have used OPC 53 grade cement in this experiment which is used as the binder

\subsection{Aggregate}

We have used Fine aggregate and coarse aggregate which helps to strengthen the concrete.

\subsection{Conplast SP 430}

It is a plasticizer used to reduce the amount of water and increases the workability when the fiber is added to the concrete.

\subsection{PVA Fibers}

Polyvinyl alcohol fibers used are manufactured evenly so that they are dispersed uniformly throughout the mix. We have used $12 \mathrm{~mm}$ length PVA fibers in concrete to increase the strength.

\subsection{BFRP rebars}

Basalt Fiber Reinforced Polymer (BFRP) rebars manufactured from a single rock from a carefully chosen quarry. They made directly without any additional admixtures as they contain high acidity. Therefore, they melted to liquid form and made into fibers then several fibers are combined using adhesive and made into rebars. The BFRP rebars shown in the Figure.

Table 1. Manufacturing details of BFRP bars.

\begin{tabular}{|l|l|}
\hline Specification & Result \\
\hline Diameter & $12 \mathrm{~mm}$ \\
\hline Weight & $219 \mathrm{gram} / \mathrm{meter}$ \\
\hline $\begin{array}{l}\text { Cross-sectional } \\
\text { area }\end{array}$ & $113.03 \mathrm{~mm} 2$ \\
\hline Tensile Strength & $1100 \mathrm{MPa}$ \\
\hline Ultimate Tention & $124.34 \mathrm{KN}$ \\
\hline Eleastic Modulus & $50 \mathrm{GPa}$ \\
\hline
\end{tabular}




\begin{tabular}{|l|l|}
\hline Limiting Strain & $2.20 \%$ \\
\hline
\end{tabular}

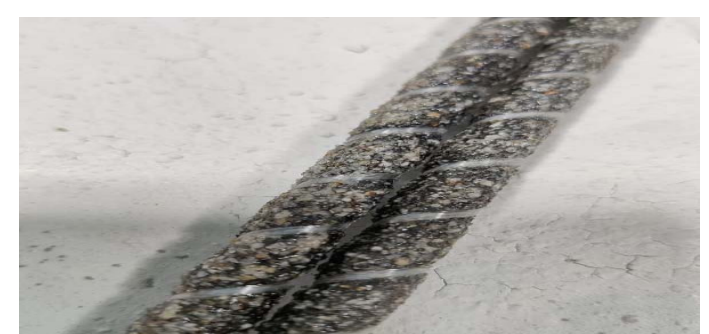

Figure 2. BFRP bars

3 Mix Procedure

In this experiment, we have used M-30 grade concrete

Mix proportions of material mentioned below and the reinforcement detailing is mentioned in the table

Cement: Fly Ash: Fine Aggregate: Coarse Aggregate: Water = 1:0.25:2.29:4.24:0.43

Table 2. Reinforcement details used in the beams

\begin{tabular}{|l|l|l|l|l|l|l|l|l|l|}
\hline \multirow{2}{*}{ Beam } & $\begin{array}{l}\text { Main } \\
\text { Reinforcement }\end{array}$ & $\begin{array}{l}\text { Bar Size } \\
\text { (mm) }\end{array}$ & Fck (N) & Af & As & Af/As & Pf(Af/bd) & Ps(As/bd) \\
\hline $\begin{array}{l}\text { Prure } \\
\text { FRP }\end{array}$ & $4 \varphi 12$ & - & 12 & 30 & 452.29 & - & - & 0.010 & - \\
\hline $\begin{array}{l}\text { HFRP } \\
\text { O PVA }\end{array}$ & $2 \varphi 12$ & $2 \varphi 12$ & 12 & 30 & 226.19 & 226.19 & 1 & 0.005 & 0.005 \\
\hline $\begin{array}{l}\text { HFRP } \\
\text { O.125 } \\
\text { PVA }\end{array}$ & $2 \varphi 12$ & $2 \varphi 12$ & 12 & 30 & 226.19 & 226.19 & 1 & 0.005 & 0.005 \\
\hline $\begin{array}{l}\text { HFRP } \\
\text { O.25 } \\
\text { PVA }\end{array}$ & $2 \varphi 12$ & $2 \varphi 12$ & 12 & 30 & 226.19 & 226.19 & 1 & 0.005 & 0.005 \\
\hline $\begin{array}{l}\text { HFRP } \\
\text { 0.375 } \\
\text { PVA }\end{array}$ & $2 \varphi 12$ & $2 \varphi 12$ & 12 & 30 & 226.19 & 226.19 & 1 & 0.005 & 0.005 \\
\hline $\begin{array}{l}\text { HFRP } \\
\text { 0.50 } \\
\text { PVA }\end{array}$ & $2 \varphi 12$ & $2 \varphi 12$ & 12 & 30 & 226.19 & 226.19 & 1 & 0.005 & 0.005 \\
\hline
\end{tabular}

\subsection{Mix Design}

We have designed an under-reinforced beam with 2 nos of $10 \mathrm{~mm}$ dia steel as top reinforcement and 4 nos $12 \mathrm{~mm}$ dia rebars. I have used BFRP rebars also in this experiment. I casted a Pure FRP beam that is I have placed 4 BFRP as the bottom and used it as a control beams. In hybrid FRP beams, I have replaced the corner steel bars with basalt fiber rebars. The design of the beam is as shown in figure 2 . The dimensions of the beam are $300 \mathrm{~mm}$ depth $150 \mathrm{~mm}$ width and $1.5 \mathrm{~m}$ length. We have used $8 \mathrm{~mm}$ steel rebars as stirrups. These are tied using 8gauge binding wire.

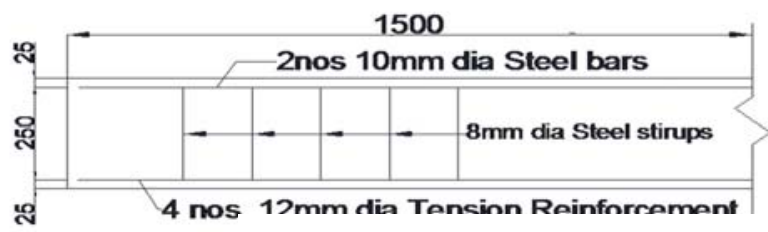

Figure a

beam and other beams are hybrid FRP
Figure 3. Illustrative diagrams of hybrid reinforced beams :
a) Reinforcement Detailing
b) HFRP beam
c) Pure FRP 


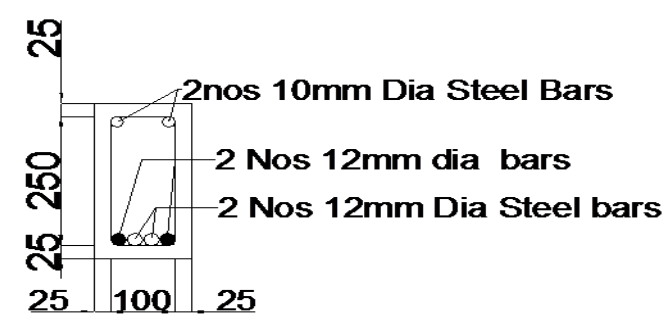

Figure b

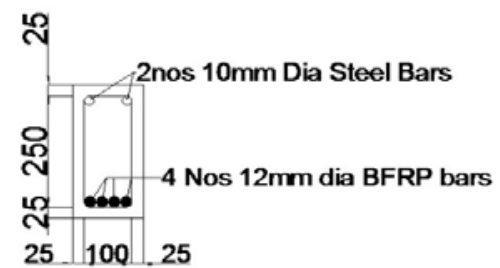

Figure c

\subsection{Mixing of Concrete}

We have mixed the material with a mixing machine. The Material has been mixed thoroughly.

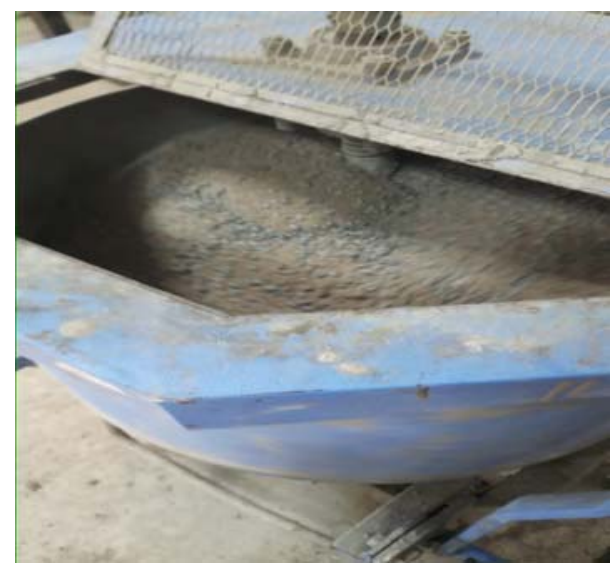

Figure 4. Mixing of Concrete

\subsection{Casting of Specimen}

We have used the moulds and placed the reinforcement in the mould with a cover of $25 \mathrm{~mm}$ on all the sides. Then the concrete is placed in the mould Figure 5. Then we used an electric needle vibrator to vibrate the concrete in mould figure 6 .

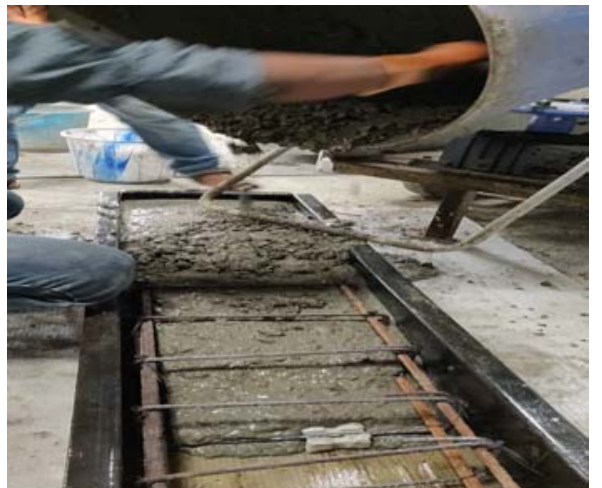

Figure 5. Placing of concrete in the mould

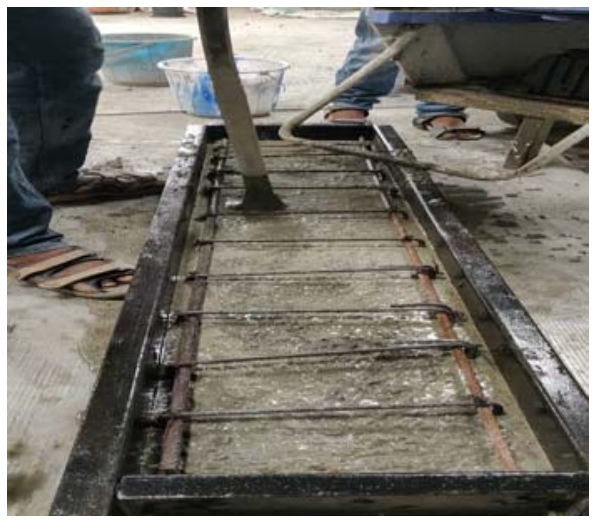

Figure 6. Vibrating the concrete

\subsection{Curing of the Specimen}

Once the Specimen is casted, we have waited for one day so that the concrete gets hardened. Then we have used a curing compound for the curing of concrete with a thick coating so that all parts of specimens cover.

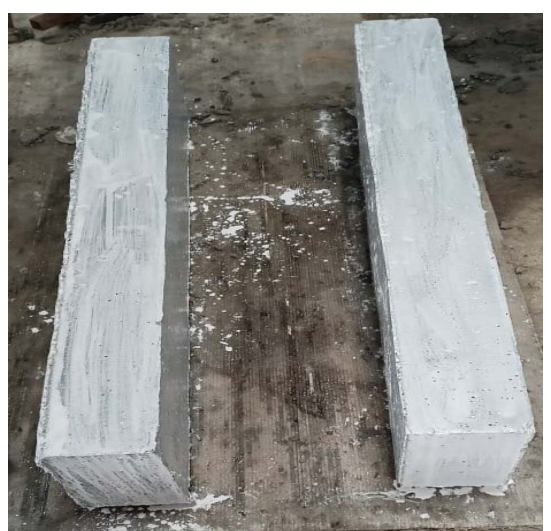

Figure 7. Curing of the specimen

\section{Experimental Procedure}

In this experiment, we have casted 7 Beams in which 2 beams are control beams and the rest 6 beams are hybrid beams with different percentages of PVA fibers. I have tested these beams using 4-point load testing machine. 
Then I have connected the Load deflection gauge to the beam. One is placed at the centre and another one is placed at the support. The experiment setup is shown in figure 8 .

\section{Results and Discussion}

\subsection{Load-deflection}

We have applied 4-point load on the specimen as shown in the experimental setup. When the load is applied then the beam is deflected the deflection is calculated using the LDT which is connected at the bottom. The loaddeflection curve is shown below of different Samples.

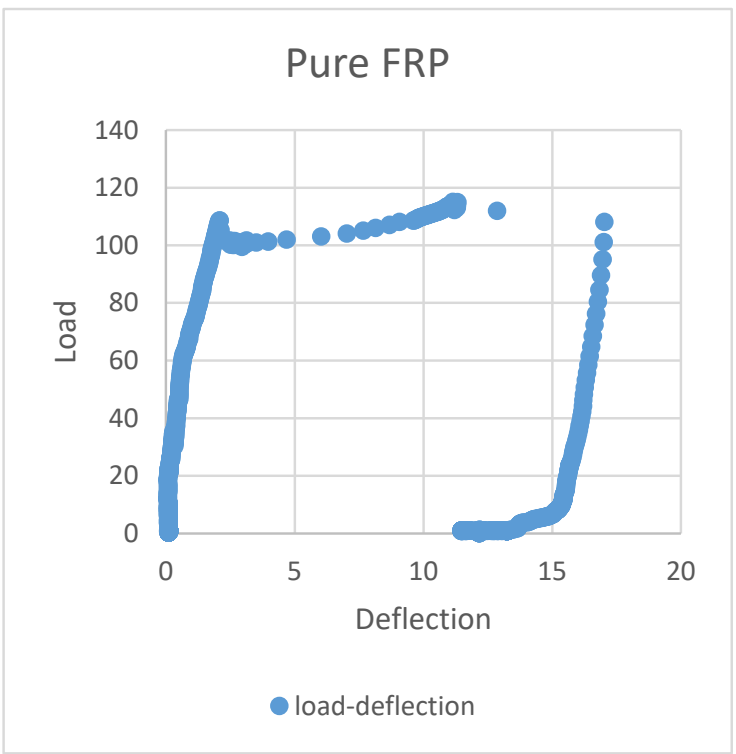

Figure 9. Load deflection curve of Pure FRP Beam

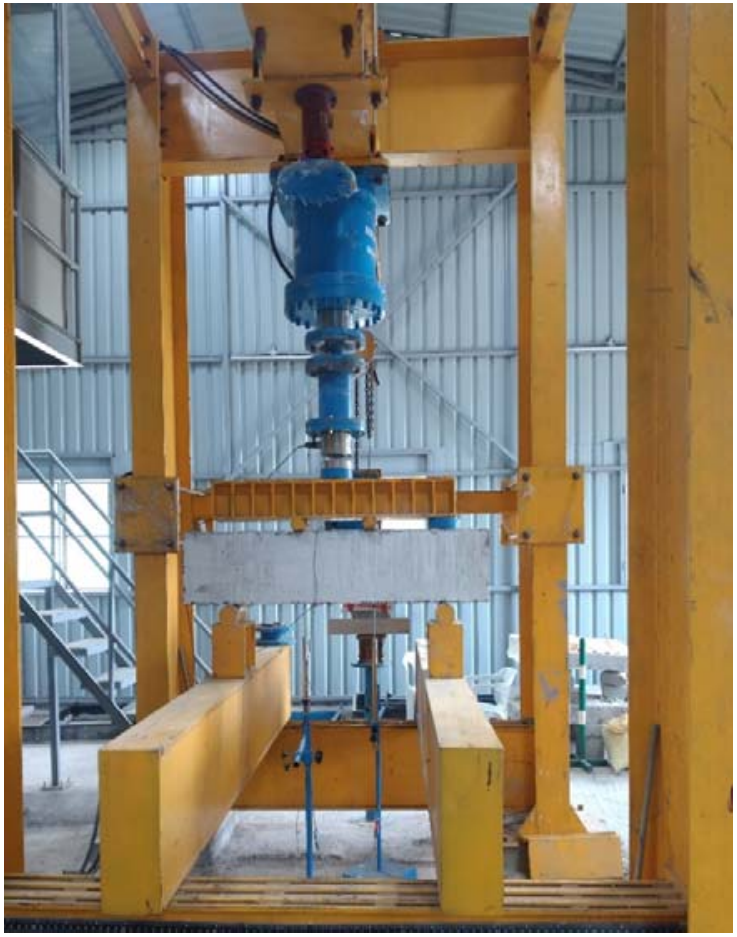

Figure 8. Test setup for testing the specimen

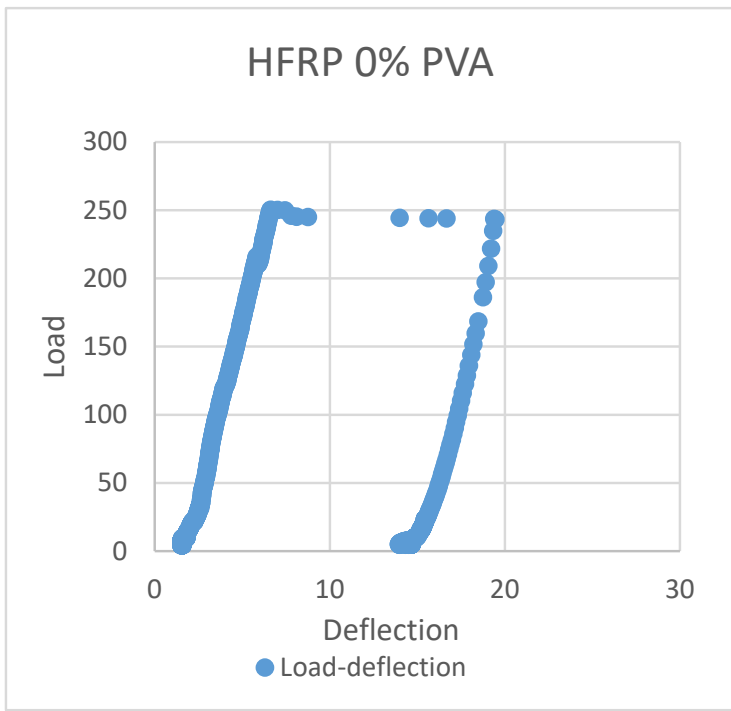

Figure 10. Load Deflection curve of HFRP 0\% PVA 


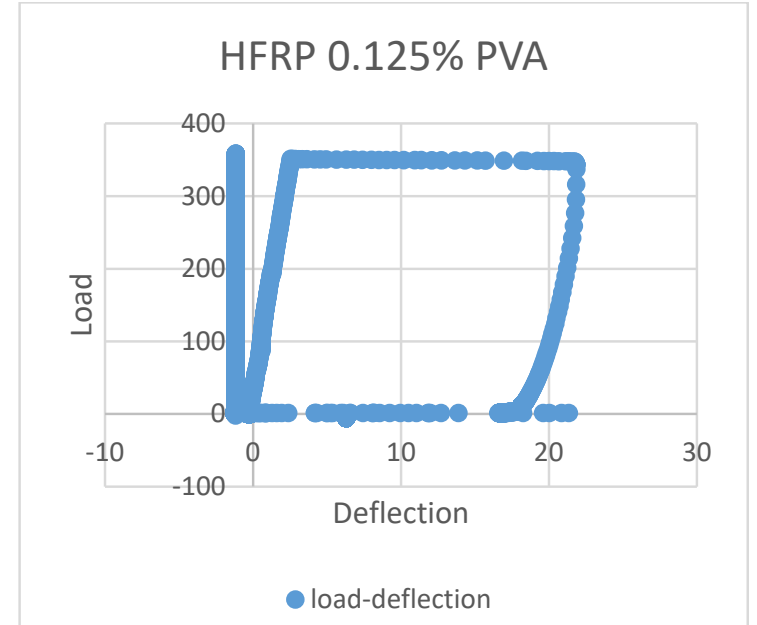

Figure 11. Load Deflection curve of HFRP $0.125 \%$ PVA

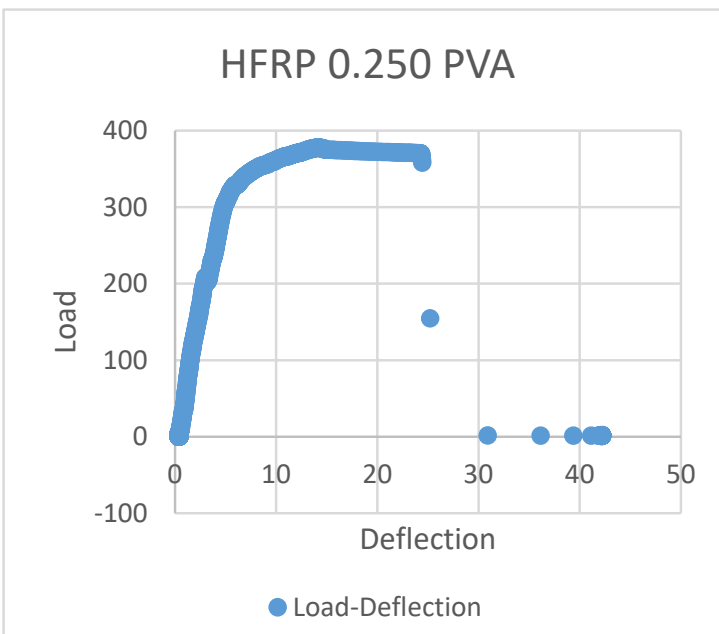

Figure 12.Load Deflection Curve of HFRP 0.250\%PVA

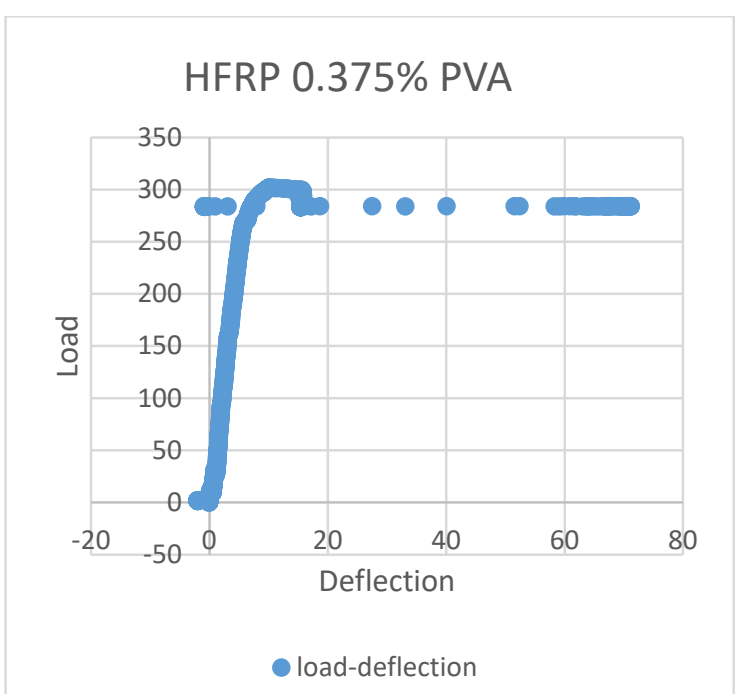

Figure 13 Load Deflection Curve of HFRP 0.375\% PVA
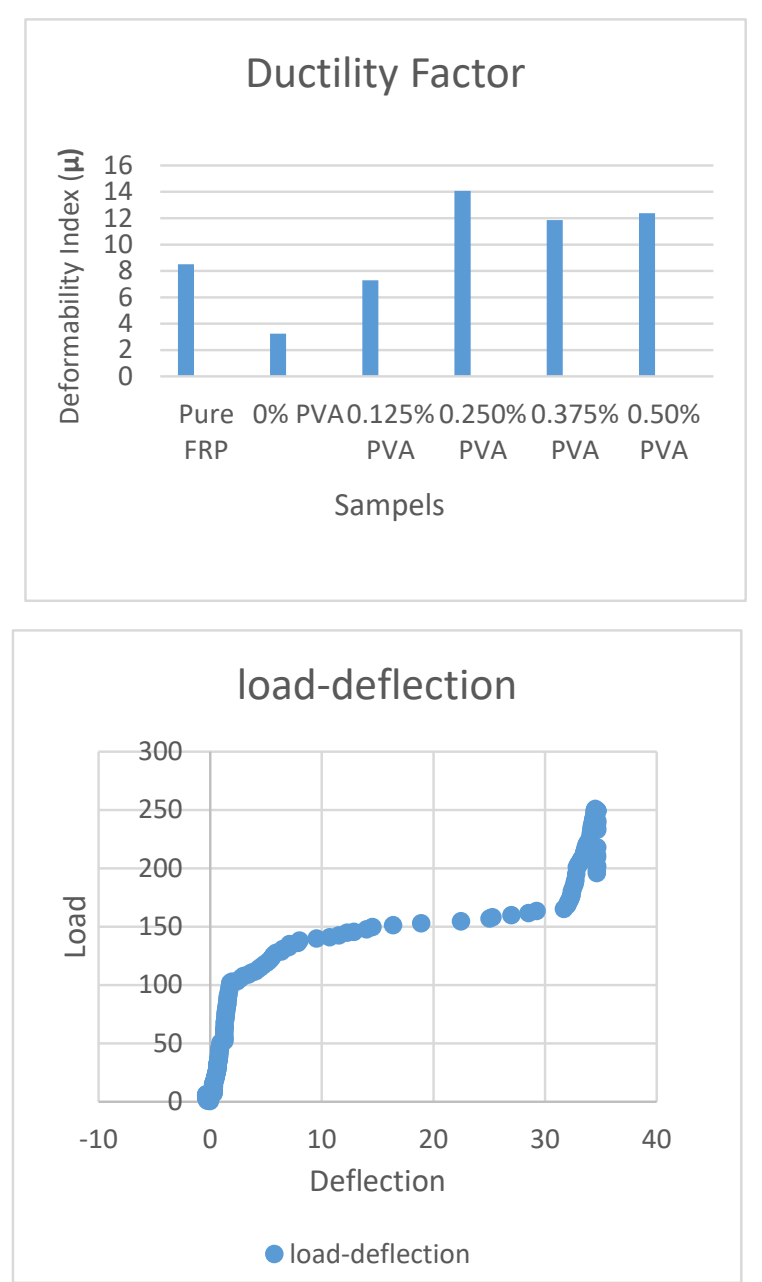

Figure 14. Load Deflection Curve of HFRP 0.50\%PVA 


\subsection{Comparative Study}

We are studying the comparison of the behaviour of the load-deflection with the help of graphs and the comparison is mentioned in the following graph.

Figure 15. Comparative study of ductility Factor

\subsection{Ductility Factor}

The ability of a material that can stretch to the maximum before the material failed is known as ductility. The ductility is calculated using the experiment and is tabulated below

Ductility Factor DI $(\mu)=\frac{\text { Yield Deflection }(\Delta y)}{\text { Ultimate deflection }(\Delta u)}$

Figure16. Ductility Factors of the Beams.

Table 3. Ductility Factor of beam

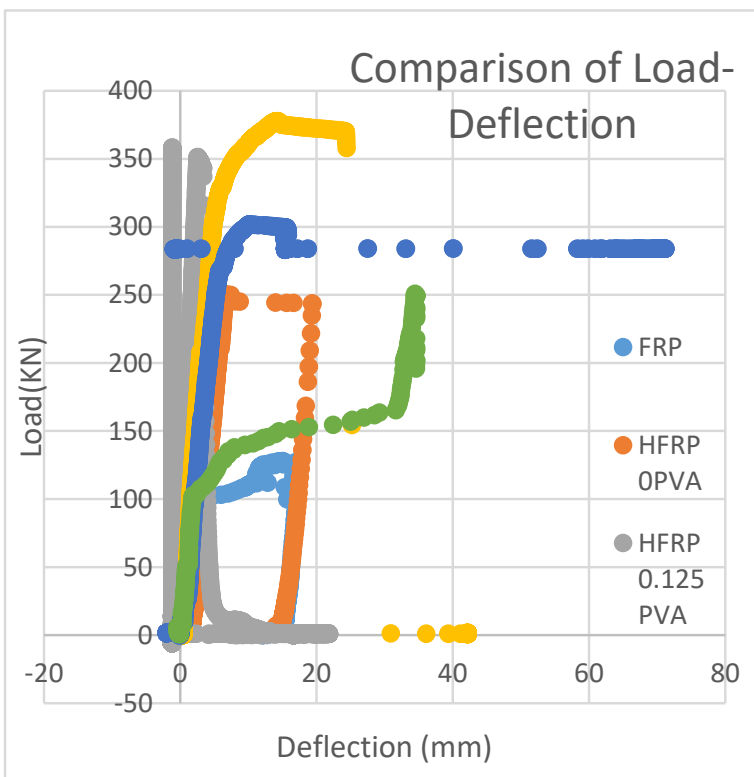

\subsection{Flexural Behaviour of reinforced concrete} beams.

The HFRP beam is placed on the testing machine on which the load is applied. The flexural behaviour is studied using the ultimate load and ultimate moment.

Table 4. Ultimate Load and Moment of Beams

\begin{tabular}{|l|l|l|}
\hline Sample & $\begin{array}{l}\text { Ultimate } \\
\text { Load }\end{array}$ & $\begin{array}{l}\text { Ultimate } \\
\text { moment }\end{array}$ \\
\hline Pure FRP & 115 & 28.75 \\
\hline
\end{tabular}

\begin{tabular}{|l|l|l|}
\hline HFRP 0\% PVA & 250.3 & 62.575 \\
\hline $\begin{array}{l}\text { HFRP 0.125\% } \\
\text { PVA }\end{array}$ & 357.9 & 89.475 \\
\hline $\begin{array}{l}\text { HFRP 0.250\% } \\
\text { PVA }\end{array}$ & 377.4 & 94.35 \\
\hline $\begin{array}{l}\text { HFRP 0.375\% } \\
\text { PVA }\end{array}$ & 301.7 & 75.425 \\
\hline $\begin{array}{l}\text { HFRP 0.50\% } \\
\text { PVA }\end{array}$ & 25.7 & 62.675 \\
\hline
\end{tabular}

\begin{tabular}{|l|l|l|l|l|}
\hline S No & Sample & $\Delta \mathrm{y}$ & $\Delta \mathrm{u}$ & $\mu$ \\
\hline 1 & Pure FRP & 2 & 17.03 & 8.515 \\
\hline 2 & HFRP 0\% PVA & 6 & 19.46 & 3.2433 \\
\hline 3 & $\begin{array}{l}\text { HFRP 0.125\% } \\
\text { PVA }\end{array}$ & 3 & 21.87 & 7.29 \\
\hline 4 & $\begin{array}{l}\text { HFRP 0.250\% } \\
\text { PVA }\end{array}$ & 3 & 42.21 & 14.07 \\
\hline 5 & $\begin{array}{l}\text { HFRP 0.375\% } \\
\text { PVA }\end{array}$ & 6 & 71.19 & 11.856 \\
\hline 6 & $\begin{array}{l}\text { HFRP 0.50\% } \\
\text { PVA }\end{array}$ & 2.8 & 34.64 & 12.37 \\
\hline
\end{tabular}

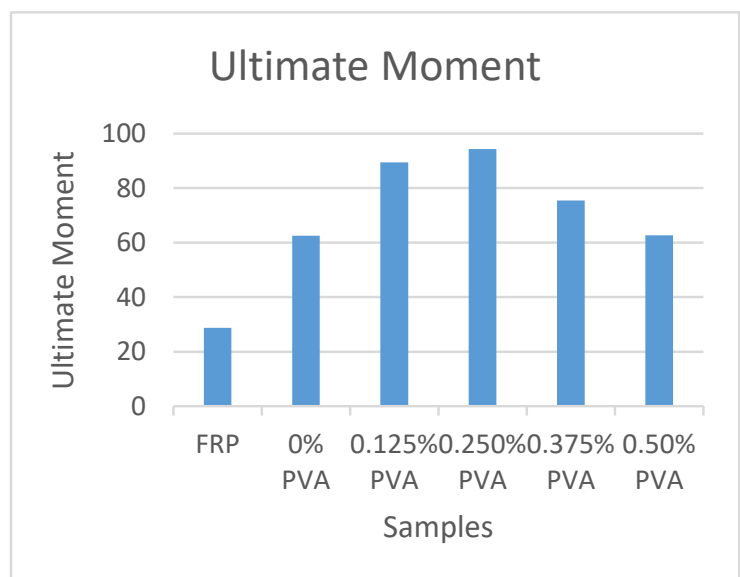

Figure 17. Ultimate moment of the Beams

\section{Conclusion}

The flexural behaviour of BFRP steel-reinforced concrete beams was tested. To reduce the risk of steel 
corrosion in concrete hybrid, a reinforcement method was proposed and used to replace the steel bars with BFRP bars. Based on the experimental results, the following conclusions can be drawn from this study

- The test results show the Hybrid FRPRC beam with PVA fibers behave in a more ductile manner when compared with the pure FRPRC beam and Hybrid FRP beam without PVA fiber.

- The Provision of PVA fibers exhibits an enhancement in the cracking load and the load-carrying capacity of the tested beams.

- The enhancement of Ultimate moment capacity is $42.99 \%$ and $211.2 \%$ at a dosage of $0.125 \%$ of PVA fibers when compared with Hybrid Reinforced concrete beam without fibers and pure BFRP.

- The ductility Factor is increased by $65 \%$ at optimum dosage of $0.25 \%$ of PVA fibers in hybrid Reinforced concrete beams when compared with pure BFRP beams.

- The addition of steel reinforcement can improve the flexural ductility of FRPRC me in the design of FRPRC members.

\section{Reference}

1. Xingyu, Gu, Dai Yiqing, and Jiang Jiwang. Eng. Struct. 206 (2020): 110117.

2. Yang, Yang, et al. Mater. Struct. 53.4 (2020): 115.

3. Zhou, Yingwu, et al. Materials 13.1 (2020): 234.

4. Attia, Karim, Ahmed El Refai, and Wael Alnahhal. Journal of composites for construction 24.2 (2020): 04020007.

5. Lu, C. H., et al. IOP Conference Series: Materials Science and Engineering. Vol. 770. No. 1. IOP Publishing, 2020.

6. Sun, Zeyang, et al. Eng. Struct. 197 (2019): 109443.

7. Zhao, Yajun, et al. Advances in Structural Engineering 23.6 (2020): 1154-1167.

8. Ren, Yanru. IOP Conference Series: Materials Science and Engineering. Vol. 768. No. 3. IOP Publishing, 2020.

9. Koniki, S. and Prasad, D.R., 2019. Journal of Building Pathology and Rehabilitation, 4(1), pp.1-8.

10. Araba, Almahdi Mohamed, and AshrafF. Ashour. Composites Part B: Engineering 154 (2018): 321 336.

11. Maranan, G. B., et al Engineering Structures 182 (2019): 141-152.

12. Mustafa, Suzan AA, and Hilal A. Hassan. HBRC journal 14.3 (2018): 300-308.
13. Zhu, Peng, et al. Journal of Composites for Construction 21.5 (2017): 04017036.

14. Qin, Renyuan, Ao Zhou, and Denvid Lau. Composites Part B: Engineering 108 (2017): 200209.

15. Koniki, S. and Prasad, D.R., 2019. Construction and Building Materials, 207, pp.238-248.

16. Sun, Z. Y., et al. Journal of Reinforced Plastics and Composites 31.24 (2012): 1737-1745.

17. Yoo, Doo-Yeol, Nemkumar Banthia, and YoungSoo Yoon. Engineering Structures 111 (2016): 246-262.

18. Kara, Ilker Fatih, Ashraf F. Ashour, and Mehmet Alpaslan Köroğlu. Composite Structures 129 (2015): 111-121.

19. El Refai, Ahmed, Farid Abed, and Abdullah AlRahmani. Construction and Building Materials 96 (2015): 518-529.

20. T.Srinivas and M. Abinay Raj, Int. J. of Eng.and Adv. Tech. (IJEAT), ISSN: 2249 - 8958, Volume-8 Issue-6 (2019)

21. T.srinivas and P. Manoj Anand, Int. J. of Innov. Tech. and Explor. Eng.g (IJITEE), ISSN: 22783075, Volume-8 Issue-12 (2019)

22. T.Srinivas and G. Sukesh Reddy, Int. J. of Eng.and Adv. Tech. (IJEAT), ISSN: 2249 - 8958, Volume-9 Issue-1 (2019)

23. T.Srinivas and R. N. Koushik, Int. J. of Innov. Tech. and Explor. Eng.g (IJITEE), ISSN: 22783075, Volume-8 Issue-12 (2019), PP 112-117.

24. K. Sai Gopi, Dr. T. Srinivas and S. P. Raju V, E3S Web of Conferences ICMED 184, 01084GRIET, 28-29

February, https://doi.org/10.1051/e3sconf/2020184011084( 2020)

25. Jagannadha Kumar, M.V., Jagannadha Rao, K., Dean Kumar, B., Srinivasa Reddy, V., Int. J. of Civil Eng. and Tech., 9(7), pp. 1133-1141 (2018)

26. Ganta, J.K., Seshagiri Rao, M.V., Mousavi, S.S., Srinivasa Reddy, V., Bhojaraju, C., Structures 28, pp. 956-972 (2020)

27. Naidu, K.S.S.T., Rao, M.V.S., Reddy, V.S., Int. J. of Innov. Tech. and Explor. Eng.g (IJITEE), 8(9 Special Issue 2), pp. 641-642 (2019)

28. Chandana Priya, C., Seshagiri Rao, M.V., Srinivasa Reddy, V., Int. J. of Civil Eng. and Tech., 9(11), pp. 2218-2225 (2018)

29. Satya Sai Trimurty Naidu, K., Seshagiri Rao, M.V., Srinivasa Reddy, V., Int. J. of Civil Eng. and Tech., 9(11), pp. 2383-2393 (2018)

30. Supriya, Y., Srinivasa Reddy, V., Seshagiri Rao, M.V., Shrihari, S., Int. J. of Rec. Tech. and Engi., 8(3), pp. 5381-5385 (2019)

31. Kotkunde, N., Krishna, G., Shenoy, S.K., Gupta, A.K., Singh, S.K. International Journal of Material Forming, 10 (2), pp. 255-266 (2017)

32. Govardhan, D., Kumar, A.C.S., Murti, K.G.K., Madhusudhan Reddy, G. Materials and Design, 36, pp. 206-214. (2012)

33. Kumar, P., Singhal, A., Mehta, S., Mittal, A. Journal of Real-Time Image Processing, 11 (1), pp. 93-109. (2016) 
34. Raghunadha Reddy, T., Vishnu Vardhan, B., Vijayapal Reddy, P. International Journal of Applied Engineering Research, 11 (5), pp. 30923102 (2016)

35. Hussaini, S.M., Krishna, G., Gupta, A.K., Singh, S.K. Journal of Manufacturing Processes, 18, pp. 151-158 (2015) 